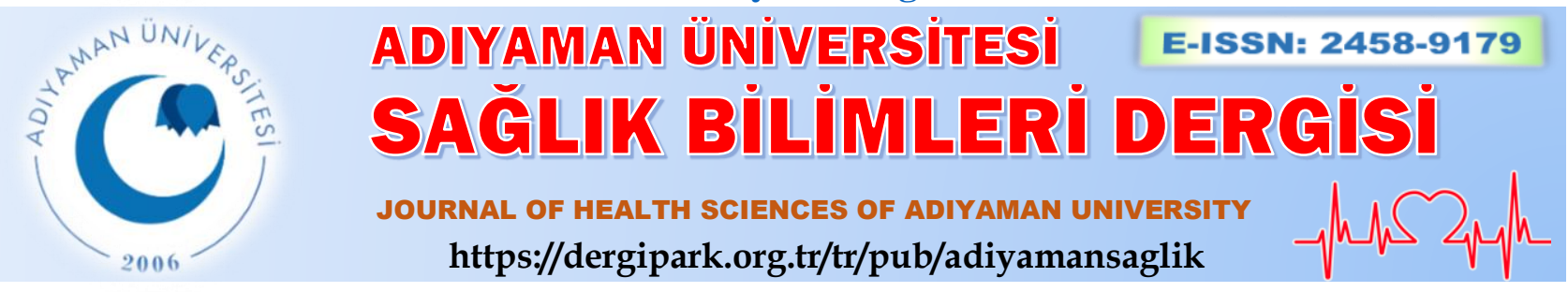

\author{
Özgün Araştırma/Research Article
}

\title{
Yeni kurulan bir çocuk nöroloji kliniğinde West Sendrom'lu olguların retrospektif olarak değerlendirilmesi
}

\section{Retrospective analysis of patients with West Syndrome in a newly established pediatric neurology clinic}

\author{
Hilal AYDIN $@$ (D) İbrahim Hakan BUCAK ${ }^{2}$ \\ ${ }^{1}$ Balıkesir Üniversitesi, Tıp Fakültesi, Çocuk Sağlı̆̆ı ve Hastalıkları Anabilim Dalı, 10145, Balıkesir-Türkiye \\ ${ }^{2}$ Adıyaman Üniversitesi, Tıp Fakültesi, Çocuk Sağlığı ve Hastalıkları Anabilim Dalı, 02040, Adıyaman-Türkiye
}

Atıf gösterme/Cite this article as: Aydin H, Bucak İH. Yeni kurulan bir çocuk nöroloji kliniğinde west sendromlu olguların retrospektif olarak değerlendirilmesi. ADYÜ Sağllk Bilimleri Derg. 2020;6(2):161-166. doi:10.30569.adiyamansaglik. 710597

Öz

Amaç: West sendromu (WS), spazm şeklindeki nöbetlere elektroensefalografide interiktal dönemde hipsaritmi paterninin eşlik etmesi ve ağır mental geriliğe yol açması ile tanımlanmaktadır.

Gereç ve Yöntem: 01 Nisan 2018-30 Haziran 2019 tarihleri arasında Adıyaman Üniversitesi Eğitim ve Araştırma Hastanesi, Çocuk Nöroloji Polikliniğine başvuran ve elektroensefalografik inceleme ve klinik bulgular ile West Sendromu tanısı konulan 12 hasta çalışmaya dâhil edildi.

Bulgular: Çalışmaya alınan 12 hastanın 7'si kız $(\% 58,4), 5$ 'i $(\% 41,6)$ erkek idi. Bütün hastaların fizik muayanesindeki ortak bulgu; hipotonisite ve kaba/dismorfik yüz görünümü idi.

Sonuç: Dokuz ay süreli izlemde West Sendrom'lu hastalarda çoklu antiepileptik ilaç kullanılmasına rağmen nöbetleri kontrol altına alınamadı ve bu olgularda değişen derecelerde psikomotor gerilik izlendi.

Anahtar Kelimeler: West Sendromu; Çocuk; Nöromotor gelişim geriliği.

\begin{abstract}
Aim: West syndrome (WS), is characterized by spasm seizures accompanied by a pattern of hypsarrhythmia on electroencephalography in the interictal period, leading to severe mental retardation.

Materials and Methods: The study included 12 patients admitted to the Pediatric Neurology Clinic of Adryaman University Hospital between 01 April 2018 and 30 June 2019 and diagnosed with West Syndrome as a result of electroencephalographic study and clinical findings.

Results: Of the 12 patients included in the study, 7 were female $(58.4 \%)$ and $5(41.6 \%)$ were male. The common finding on physical examinations of all patients was hypotonicity and coarse/dysmorphic facial appearance.
\end{abstract}

Conclusion: During the nine follow-up, patients with West syndrome could not be kept under control despite multiple antiepileptic drugs, and varying degrees of psychomotor retardation were observed in these cases.

Keywords: West Syndrome; Child; Neuromotor retardation.

Yazışma Adresi/Address for Correspondence: Hilal AYDIN, Balıkesir Üniversitesi, Tıp Fakültesi, Çocuk Sağlığı ve Hastalıkları Anabilim Dalı, Çocuk Nöroloji, 10145, Balıkesir-Türkiye, E-mail: drhilalaydin@ gmail.com

Geliş Tarihi/Received:28.03.2020 Kabul Tarihi/Accepted:01.05.2020 Yayım Tarihi/Published online:30.08.2020 


\section{Giriş}

West sendromu (WS), süt çocukluğu döneminin yaşa bağlı epileptik sendromları arasında en sık görülenidir. West Sendromu spazm şeklindeki nöbetlere elektroensefalografide interiktal dönemde hipsaritmi paterninin eşlik etmesi ve ağır mental geriliğe yol açmasıyla tanımlanır. İnsidans1, yılda onbin canlı doğumda 2-5 arasında değişir. ${ }^{1}$ Elektroklinik spazmlar (ES) genellikle kümeler halinde izlenir. WS etyolojisi, genetik, yapisal, metabolik ve bilinmeyen nedenlerle geniş ölçüde heterojendir. ${ }^{2} \mathrm{Bu}$ çalışmada yeni kurulan üçüncü basamak eğitim ve araştırma hastanesi çocuk nöroloji polikliniğinde takip edilen West Sendrom'lu hastalara ait deneyimlerimizi paylaşmayı amaçladık.

\section{Gereç ve Yöntem}

01 Nisan 2018-30 Haziran 2019 tarihleri arasında Adıyaman Üniversitesi Eğitim ve Araştırma Hastanesi, Çocuk Nöroloji Polikliniğine başvuran ve West Sendromu tanısı konulan 12 hasta çalışmaya dahil edildi. Hastaların pre-, peri- ve postnatal ayrıntılı anamnezleri alınarak fizik muayeneleri yapıldı. Elektroensefalografik (EEG) inceleme ve klinik bulgularıyla birlikte değerlendirilerek WS tanısı konuldu. Nöroradyolojik inceleme yöntemi olarak kranial magnetik rezonans görüntülemesi (MRG) kullanıldı. Hastaların metabolik tetkikleri (idrar-kan aminoasitleri, tandem MS aminoasit ve açil karnitin, idrarda organik asitleri, amonyak, laktat ve kan gazi), tüm batın ultrasonografisi (USG), rutin göz muayeneleri, genetik incelemeleri planlandi. Nöbetlerin başladığı dönemde ACTH ve B6 vitamin tedavileri düzenlendi. Kliniğimizde ACTH tedavisi, 10 kilogram $(\mathrm{kg})$ altındaki hastalara 0,5 miligram $(\mathrm{mg}), 10 \mathrm{~kg}$ ve üzerindeki hastalara $1 \mathrm{mg}$ dozda, ilk 4-6 hafta haftada 2 doz, sonraki 2-4 hafta haftada $1 \mathrm{doz}$, sonraki 4 hafta 2 haftada bir doz, daha sonra da 1 ya da 2 ay süreyle ayda bir doz olmak üzere, nöbet kontrolü ve EEG' deki düzelmeye göre toplam 13-20 doz olarak uygulandi. ACTH tedavi sonrasinda nöbetsizlik zamanları kayıt altına alındı. ACTH tedavi sonrası tekrar nöbetleri başlayan hastaların antiepileptik ilaç düzenlemeleri yapıldı.
Ortalama 9 aylık izlem sürecinde nöromotor gelişimleri izlendi. Psikomotor gelişimleri Ankara Gelişim Tarama Envanteri (AGTE) ya da Denver II Gelişimsel Tarama Testi ile değerlendirildi. Bu testlerin sonuçlarına göre olgular hafif, orta ve ağır gerilik olarak tanımlandı. $\mathrm{Bu}$ çalışma yerel etik kurul tarafından onayland1 (izin no:2020/1-33). Araştırma Helsinki Bildirgesi ilkelerine göre yürütüldü. Retrospektif çalışma olduğundan dolayı hasatalardan bilgilendirilmiş onam alınamadi.

\section{Bulgular}

Çalışmaya alınan 12 hastanın 7'si kız $(\% 58,4), \quad 5$ 'i $\quad(\% 41,6) \quad$ erkekti. Konvülziyonların başlama yaşı ortalama 4,7 ay ve ortalama tanı alma yaşı 4,9 ay olarak saptandi. Olguların tamamında prenatal dönemde özellik bulunmadığı ve miad doğdukları öğrenildi. Üç hastanın (\%25) $<3000$ gr, 1 hastanın $(\% 8,3)>4000$ gr ve 8 hastanın (\%66,3) 3000-4000 gr arasinda doğduğu belirlendi. Olguların 5'i $(\% 41,6)$ sezaryan ile 7 'sinin $(\% 58,4)$ ise normal spontan vaginal yol ile ve tüm hastaların hastanede dünyaya geldiği öğrenildi. Postnatal dönemde olguların 7'sinde $(\% 58,4)$ özellik bulunmazken, 5'inde $(\% 41,6)$ kuvöz kalış öyküsü olduğu tespit edildi. Beş olgunun birinde postnatal 6 . saatte myoklonik nöbetlerin başladığı, ikisinde solunum sıkıntısı ve iki tanesinin de sepsis nedeni ile >30 günden fazla yenidoğan yoğun bakım servisinde yatarak tedavi edildiği belirlendi. Ayrıca bu beş hastadan ikisinin 30 günden uzun süren mekanik ventilatör desteği aldığ öğrenildi. Beş $(\% 41,6)$ hastada ailede akrabalık öyküsü varken, 7 hastada $(\% 58,4)$ akrabalık öyküsü bulunmadığı belirtildi. Altı olgunun (\%50) ailesinde epilepsi öyküsü mevcuttu. Olguların tamamında fizik muayenede; hipotonisite (trunkal, yaygin, alt ekstremitede) ve kaba/dismorfik yüz görünümü bulunması dikkat çekici idi. En sık ikinci fizik muayene bulgusu; olguların göz takibinin olmamasıydı. Yedi $(\% 58,4)$ olguda mikrosefali mevcut iken diğer 5 olgunun baş çevresi 0,-2 SD arasındaydı. Hiçbir hastamızda makrosefali izlenmedi. Olguların fizik muayene bulgularının dağılımı Şekil 1 'de paylaşı1mıştır. 


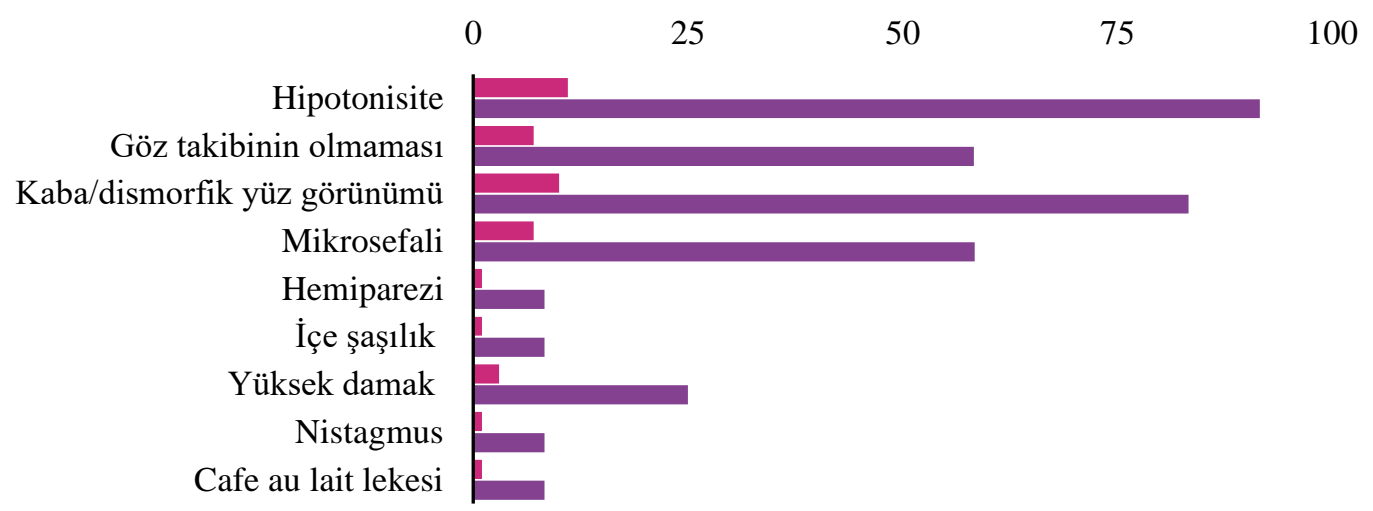

Şekil 1. Olgularımızın fizik muayane bulgularının dağılımı.

Olguların poliklinik başvuru şikayetleri incelendiğinde; 9 hasta (\%75) nöbet geçirme, 3 hasta (\%25) ise gelişme geriliği ile başvurmuş idi. Çalışmaya dahil edilen olguların 9'unda fleksör, 2'sinde ekstansör, 1 'inde ise mikst tipte epileptik spazm var idi. On bir hastamızın metabolik tetkikleri (idrar kan aminoasitleri, kan gazı, amonyak, laktat, idrar organik asitleri, tandem MS aminoasit ve açil karnitin) normal iken, bir hastamıza nonketotik hiperglisinemi tanıs1 konuldu. Olguların tamamında EEG'de tipik hipsaritmi bulgusu izlendi. Bir hastamıza teknik yetersizlik nedeni ile kranial görüntüleme çekilemedi ve MR çekilmesi için daha ileri bir merkeze yönlendirildi. On bir hastanın 2'sinde kranial görüntüleme normal iken, üçünde kortikal displazi ve 6'sında değişen derecelerde serebral/serebeller atrofi, korpus kallozumda incelme, lateral ventrikülde atrofiye sekonder genişleme saptandı. Sadece bir hastanın $(\% 8,4)$ batın ultrasonografisinde sol böbrek toplayıc1 sistemde grade 1 genişleme izlendi.

Ortalama izlem süresi 9 ay olarak saptanan olgularda değișen derecelerde nöromotor gelişim geriliği saptandı. Beş hastada $(\% 45,4)$ ağır, 3 hastada orta $(\% 27,2)$ ve 3 hastada hafif gelişim geriliği $(\% 27,2)$ mevcuttu. 10 hastaya ACTH protokolu başlanıldı. İkinci en sıklıkla başlanılan anti-epileptik vigabatrin idi. ACTH tedavi sonrası nöbetsizlik izlem süresi 4,45 aydı. ACTH tedavi sonrası nöbetleri başlayan 9 olguda 2-4'lü antiepileptik kullanımı (klobazam, klonazepam, levetirasetam, valproik asit) mevcuttu. Sadece 2 hastada $(\% 16,6)$ tekli anti-epileptik ilaçla nöbetleri kontrol altına alındı. 2 hastamız $(\% 16,6)$ takipleri sırasında exitus oldu. 2 hastamiz $(\% 16,6)$ hipoksik iskemik ensefalopati, 2 hastamız $(\% 16,6)$ kortikal displazi, 1 hastamız $(\% 8,3)$ nonketotik hiperglisinemi, 1 hastamız da $(\% 8,3)$ 1p 36 delesyon sendromu mevcuttu. Olgularımıza ait klinik, laboratuvar ve fiziksel özellikler Tablo 1'de paylaşılmıştır.

\section{Tartışma}

Klasik WS triad1, infantil spazmlar, gelişme geriliği ve EEG'de hipsaritmi paternidir. $^{2}$ Epileptik spazmlar infantlarda en sık görülen epileptik sendromlardan biridir ve insidansı yaklaşı 2-5/10.000' dir. $^{2}$ WS olgularda klinik bulgu başlangıç yaşı 3-12 aydır (pik yaşı: 5 ay). ${ }^{3}$ Bizim olgularımızda nöbet başlama yaşı ortalama 4,7 ay iken tanı alma yaşı ortalama 4,9 ay idi. Erkek cinsiyette WS daha fazla izlenmektedir (\%60). ${ }^{1}$ Bizim çalışmamızda literatürün aksine kız olgular $(\% 58,4)$ çoğunluğu oluşturmaktaydı. Bu bulgunun olgu sayımızın düşük olmasından kaynaklandığını düşünmekteyiz.

İnfantil spazmlar semptomatik ve kriptojenik/idiopatik olmak üzere ikiye ayrılmaktadır. Herhangi bir risk faktörü bulunmayan, spazmlar öncesi psikomotor gelişimi normal olan, nöro-görüntüleme ve ayrıntılı metabolik incelemeler ile etyolojik neden saptanamayan hastalar kriptojenik, etyolojisi belirlenebilenler ise semptomatik West sendromu olarak tanımlanır. ${ }^{3}$ WS etyolojisi metabolik, yapısal (örn. hipoksikiskemik ensefalopati, serebrovasküler olaylar, intrakraniyal enfeksiyon) ve genetik nedenler dahil olmak üzere heterojendir. ${ }^{2}$ Prognozu genellikle altta yatan neden belirlemektedir. ${ }^{4}$ 
Tablo 1. Olgularımızın klinik, laboratuvar özellikleri.

\begin{tabular}{|c|c|c|c|c|c|c|c|c|}
\hline & Cins & $\begin{array}{l}\text { Spazm } \\
\text { türü }\end{array}$ & $\begin{array}{l}\text { Spazm } \\
\text { başlama } \\
\text { ay }\end{array}$ & $\begin{array}{l}\text { Gelişim } \\
\text { geriliği }\end{array}$ & Atipik özellikler & Kranial MR & $\begin{array}{l}\text { Metabolik } \\
\text { Tetkikler }\end{array}$ & AEİ \\
\hline H.K & $\mathrm{E}$ & $\mathrm{F}$ & 1 & Ağır & $\begin{array}{l}\text { Dismorfik yüz, } \\
\text { Hipotonisite, } \\
\text { Nistagmus, } \\
\text { Yüksek damak }\end{array}$ & $\begin{array}{l}\text { Hemimegalensefali, } \\
\text { Şizensefali, Kortikal } \\
\text { atrofi, }\end{array}$ & Normal & $\begin{array}{l}\text { VPA } \\
\text { VGB } \\
\text { TPM } \\
\text { LEV }\end{array}$ \\
\hline T.Y.Ş & $\mathrm{E}$ & $\mathrm{M}$ & 3 & Ağır & $\begin{array}{l}\text { Dismorfik yüz, } \\
\text { Hipotonisite, } \\
\text { Göz teması kısıtlı, } \\
\text { Mikrosefali }\end{array}$ & $\begin{array}{l}\text { Bilateral } \\
\text { polimikrogri }\end{array}$ & Normal & $\begin{array}{l}\text { LEV } \\
\text { VGB } \\
\text { CZM }\end{array}$ \\
\hline M.A.D & $\mathrm{E}$ & $\mathrm{F}$ & 6 & Orta & $\begin{array}{l}\text { Kaba yüz, } \\
\text { Hipotonisite, } \\
\text { Göz teması kısıtlı, } \\
\text { Yüksek damak, } \\
\text { Mikrosefali }\end{array}$ & $\begin{array}{l}\text { CC ince, } \\
\text { Serebral/Serebeller } \\
\text { atrofi, PV bölgede } \\
\text { hiperintensite }\end{array}$ & Normal & $\begin{array}{l}\text { VGB } \\
\text { LEV } \\
\text { Klonazepam }\end{array}$ \\
\hline H.F.I & $\mathrm{E}$ & $\mathrm{F}$ & 6 & Hafif & $\begin{array}{l}\text { Göz teması kısıtl1, } \\
\text { Hipotonisite }\end{array}$ & $\begin{array}{l}\text { Kortikal atrofi, LV } \\
\text { dilate }\end{array}$ & Normal & LEV \\
\hline E.İ.A & K & E & 5 & Ağır & $\begin{array}{l}\text { Sol hemiparezi, } \\
\text { Hipotonisite, } \\
\text { Kaba yüz }\end{array}$ & $\begin{array}{l}\text { Sağ frontal cevherde } \\
\text { kortikal displazi }\end{array}$ & Normal & $\begin{array}{l}\text { LEV } \\
\text { TPM }\end{array}$ \\
\hline Z.Ö & $\mathrm{K}$ & $\mathrm{E}$ & 6 & Hafif & $\begin{array}{l}\text { Hipotonisite, } \\
\text { Kaba yüz, } \\
\text { Mikrosefali }\end{array}$ & Normal & Normal & $\begin{array}{l}\text { VGB } \\
\text { TPM } \\
\text { VPA }\end{array}$ \\
\hline B.F.K & K & $\mathrm{F}$ & 4 & Orta & $\begin{array}{l}\text { Strabismus, } \\
\text { Hipotonisite, } \\
\text { Çok sayıda cafe au lait } \\
\text { lekesi, Göz teması kısıtlı }\end{array}$ & $\begin{array}{l}\mathrm{CC} \text { ince, } \\
\text { Serebeller/Serebral } \\
\text { atrofi, }\end{array}$ & Normal & $\begin{array}{l}\text { LEV } \\
\text { VGB } \\
\text { Klonazepam }\end{array}$ \\
\hline E.K & $\mathrm{E}$ & $\mathrm{F}$ & 7 & Ağır & $\begin{array}{l}\text { Kaba yüz, } \\
\text { Hipotonisite, } \\
\text { Göz teması kısıtlı }\end{array}$ & Normal & Normal & $\begin{array}{l}\text { VGB } \\
\text { VPA } \\
\text { CZM }\end{array}$ \\
\hline K.T.K & $\mathrm{E}$ & $\mathrm{F}$ & 2 & Ağır & $\begin{array}{l}\text { Kaba yüz, } \\
\text { Hipotonisite, } \\
\text { Mikrosefali }\end{array}$ & $\begin{array}{l}\text { Serebral/Serebeller } \\
\text { atrofi, PV bölgede } \\
\text { hiperintensite }\end{array}$ & Normal & $\begin{array}{l}\text { LEV } \\
\text { CZM }\end{array}$ \\
\hline G.G & $\mathrm{K}$ & $\mathrm{F}$ & 2 & Orta & $\begin{array}{l}\text { Kaba yüz, } \\
\text { Göz teması kısıtlı, } \\
\text { Mikrosefali }\end{array}$ & $\begin{array}{l}\text { Bilateral internal } \\
\text { kapsül arka } \\
\text { bacağında } \\
\text { hiperintensite }\end{array}$ & $\begin{array}{l}\text { Tandem MS; } \\
\text { glisin artışı }\end{array}$ & $\begin{array}{r}\text { CZM } \\
\text { LEV } \\
\text { TPM }\end{array}$ \\
\hline A.Ç & K & $\mathrm{F}$ & 6 & & $\begin{array}{l}\text { Yüksek damak, } \\
\text { Kaba yüz } \\
\text { Laringomalazi, } \\
\text { Hipotonisite, } \\
\text { Mikrosefali }\end{array}$ & - & Normal & VGB \\
\hline A.A & $\mathrm{E}$ & $\mathrm{F}$ & 6 & Hafif & $\begin{array}{l}\text { Hipotonisite, } \\
\text { Göz teması kısıtl1, } \\
\text { Kaba yüz, } \\
\text { Mikrosefali }\end{array}$ & $\begin{array}{l}\text { CC ince, Serebral } \\
\text { atrofi (FTbölgede) } \\
\text { LV dilatasyon }\end{array}$ & Normal & VGB \\
\hline
\end{tabular}

AEİ: Antiepileptik ilaç, F: Flexör tip, E: Ekstansör tip, M: Miskt tip, VGB: Vigabatrin, CZM: Klobazam, LEV: Levetirasetam, TPM: Topiramat, VPA: Valproik asit, LV:Lateral ventrikul CC: Korpus kallosum, FT: Frontotemporal, PV: Periventrikuler

207 WS'li infantın olduğu bir çalışmada olguların \%61'inde etyoloji saptanırken $\% 33$ 'ünde etyolojik bir neden saptanamamıştır. Etyolojisi belirlenebilen olgularda en sık; hipoksik iskemik ensefalopati (\%10), kromozomal anormallikler (\%8), malformasyonlar (\%8), perinatal inme (\%8), tüberoskleroz (\%7), periventriküler lökomalazi ile birlikte kanamalar (\%5) rapor edilmiştir. ${ }^{5}$ Bizim çalışmamızda 2 hastamız $(\% 16,6)$ hipoksik iskemik ensefalopati, 2 hastamız $(\% 16,6)$ kortikal 
displazi, 1 hastamı $(\% 8,3)$ nonketotik hiperglisinemi ve 1 hastamız da $(\% 8,3)$ 1p 36 delesyon sendromu mevcut idi. Mevcut bulgularımız literatür ile örtüşmektedir.

WS tanısı konulan olgulara ait interiktal EEG'de tipik hipsaritmi paterni görülmektedir. Hipsaritmi paterni; kaotik bir zeminde, hemisferlerin her bölgesinde görülebilen, süresi ve sıklığı değișen, yüksek amplitüdlü diken ve keskin karakterli dalgalardan oluşmaktadır. ${ }^{6}$ Bütün hastalarımızın interiktal EEG'sinde hipsaritmi paterni mevcut idi.

WS'lu hastaların kranial görüntülemesinde multifokal ensefalomalazik değişiklikler (\%15), kortikal atrofi $(\% 24,3)$, periventriküler lökomalazi $(\% 7,14)$, kalsifikasyonlar (\%10) ve gelişimsel malformasyonlar $(\% 5,7)$ saptanmıştır. ${ }^{7}$ Bizim çalışmamızda görülen kranial görüntüleme bulguları literatür bulgularını desteklemektedir.

Nöbetlerin hızlı bir şekilde kontrol altına alınabilmesi için tedaviye mümkün olan en kısa sürede başlanılması önerilmektedir. WS tanısı konulan hastalarda adrenokortikotropik hormon (ACTH), kortikosteroidler ve vigabatrin (VGB) önerilen başlica ilaçlardır. ${ }^{8}$ Adrenokortikotropik hormon (ACTH), WS'nda en iyi tedavi seçeneklerinden biri olarak bilinmektedir. ACTH'nın halen etkin dozu ve kullanım süresi ile ilgili kesin bir görüş birliği yoktur. ${ }^{9}$ ACTH'nın 20-30 IU/gün ile $150 \mathrm{IU} / \mathrm{m}^{2} /$ gün iki doz kullanımı halinde klinik cevap olarak bir farklılık izlenmemiştir. $^{10,11}$ Vigabatrin de ACTH ile birlikte en etkin ajandır. ${ }^{12} 10$ hastamıza ACTH tedavisi ve B6 vitamini tedavisi başlandı. ACTH tedavisi sonlandıktan sonra üçte bir hastada spazmlar tekrar edebilir. ${ }^{10}$ Bizim hastalarımızda ACTH tedavisi sonras1 nöbetsizlik izlem süresi 4,45 aydı. İzlemde hastaların \%50-60'1 spazm veya çeşitli tiplerdeki nöbetleri geçirmeye devam eder. Bazı hastalar ise aylar yada yıllar süren nöbetsizlik sonrası tekrar nöbet geçirmeye başlayarak epilepsi tanısı alırlar. ${ }^{13}$ İnfantil spazmlar için kullanılan diğer anti-epileptik ilaçlar; felbamat, sodyum valproat, zonisamid, topiramat, nitrazepam, levetirasetamdir. ${ }^{13}$ ACTH tedavi sonrası nöbetleri başlayan 9 hastada 3-4'lü antiepileptik ilaç kullanımı (klobazam, klonazepam, levetirasetam, valproik asit) mevcuttu. Sadece 2 hastanın $(\% 16,6)$ tekli antiepileptik ilaçla (vigabatrin, levetirasetam) nöbetleri kontrol altına alındı. Tekli antiepileptik ilaç ile nöbetleri kontrol altına alınan hastaların diğer olgulardan klinik ve radyolojik olarak hiçbir farkı olmaması dikkat çekici idi.

İlk iki y1l içinde, WS'li olgularda altta yatan etyolojiye bağlı olarak ölüm görülebilmektedir. ${ }^{14}$ İki hastamıdan biri aspirasyon pnömonisi diğeri de çoklu organ yetmezliği nedeni ile exitus oldu.

Çalışmamızın retrospektif olması, olgu sayısının az ve ortalama izlem sürelerinin kısa olması çalışmamızın kısıtlılıklarını oluşturmaktadır.

\section{Sonuç}

Yeni kurulan bir çocuk nöroloji kliniğinde WS ile ilgili deneyimlerimizi paylaştık. Sonuç olarak, dokuz ay süreli izlemde bu hastalarda çoklu antiepileptik ilaç kullanılmasına rağmen nöbetler kontrol altına alınamadı ve bu olgularda değişen derecelerde psikomotor gerilik izlendi. Bu konu ile ilgili uzun süreli takiplerin yapılacağı, çok fazla sayıda olguyu içeren, prospektif çalışmalara ihtiyaç bulunmaktadır.

\section{Araștırmanın Etik Boyutu}

$\mathrm{Bu}$ çalışmanın etik kurulu ilgili üniversitenin Tip Fakültesi Etik Kurulu'ndan etik kurul izni alınmıştır (14/01/2020 tarihli 2020/1-33 karar sayıs1). Araştırma Helsinki Bildirgesi ilkelerine göre yürütüldü.

\section{Bilgilendirilmiş Onam}

Çalışmaya dahil edilen tüm hastalardan bilgilendirilmiş onam formu alınmamıştır.

\section{Yazar Katkıları}

HA: Olguları toplama, ana metini gözden geçirme ve makaleyi derleme; İHB: İstatiksel verileri hazırlama, Ana metini gözden geçirme, makaleye son halini verme

\section{Teşekkürler}

Adıyaman İlinde Çocuk Nöroloji kliniğinin kurulmasında emeği geçen Saygıdeğer Prof. Dr. Mehmet Turgut Hocamıza en içten teşekkürlerimizi sunarız. 


\section{Çıkar Çatışması Beyanı}

Yazarların herhangi bir çıkara dayalı ilişkisi yoktur.

\section{Araștırma Desteği}

Çalışmayı maddi olarak destekleyen kişi/kuruluş yoktur.

\section{Beyanlar}

Bu çalışma 3. Trakya Üniversiteler Birliği Uluslararası Sağlık Bilimleri Kongresi, 24-26 Ekim 2019'da Çanakkale'de sözel sunum olarak sunulmuştur.

\section{Kaynaklar}

1. Pavone P, Striano P, Falsaperla R, Pavone L, Ruggieri M. Infantile spasms syndrome, West syndrome and related phenotypes: what we know in 2013. Brain Dev. 2014;36:73951.

2. Wilmshurst JM, Ibekwe RC, O 'Callaghan FJK. Epileptic spasms 175 years on: trying to teach and old dog new tricks. Seizure. 2017;44:81-6.

3. Panayiotopoulos CP. A Clinical Guide to Epileptic Syndromes and their Treatment. 2nd edition. London: Springer; 2011.

4. Heyne HO,Singh T,Stamberger $\mathrm{H}$, et al. De novo variants in neurodevelopmental disorders with epilepsy. Nat. Genet. 2018;50:1048-1053.

5. Osborne JP, Lux AL, Edwards SW, et al. The underlying etiology of infantile spasms (West syndrome): information from the United Kingdom Infan- tile Spams Study (UKISS) on contemporary causes and their classification. Epilepsia. 2010;51:2168-74.

6. Kossof EH. Infantile spasms. Neurologist. 2010;2:69-75

7. Gibbs FA, Gibbs EL. Atlas of Electroencephalography, 2nd ed. Addison-Wesley Press. Cambridge, Massachusetts Inc; 1952:222-224

8. Alonzo RD,Rigante D, Mencaroni E, Esposito S. West Syndrome: A Review and Guide for Paediatricians. Clin Drug Investig. 2018;38:113-124.

9. Pellock JM, Hrachovy R, Shinnar S, et al. Infantile spasms: a U.S. consensus report. Epilepsia. 2010;51(10):2175-89.

10. Shu X-M, Li J, Zhang G-P, Mao Q. A comparative study of conventional dose and low dose adrenocorticotrophic hormone therapy for West syndrome. $J$ Contemp Pediatr. 2009;11(6):445-8.

11. Kondo Y, Okumura A, Watanabe K, et al. Comparison of two low dose ACTH therapies for West syndrome: their efficacy and side effect. Brain Dev. 2005;27(5):326-30.

12. Fejerman N, Cersósimo R, Caraballo R, et al. Vigabatrin as a first-choice drug in the treatment of West syndrome. J Child Neurol. 2000;15(3):161-5.

13. Hrachovy RA, Frost JD. Severe encephalopathic epilepsy in infants: infantile spasms (West syndrome). In. Pellock JM, Boorgeois BF, Dodson WE, Nordi DR Jr, Sankar R. Pediatric Epilepsy: Diagnosis and Therapy. Demos Medical Publishing. New York, NY: Inc; 2008:249.

14. Sillanpaa M, Shinnar S. SUDEP and other causes of mortality in childhood onset epilepsy. Epilepsy Behav. 2013;28:249-255. 